\title{
Heavy menstrual bleeding and health-associated quality of life in women with von Willebrand's disease
}

\author{
IGOR GOVOROV $^{1}$, LENA EKELUND ${ }^{1}$, ROZA CHAIRETI ${ }^{2}$, PETRA ELFVINGE ${ }^{3}$, \\ MARGARETA HOLMSTRÖM $^{3}$, KATARINA BREMME ${ }^{1}$ and MIRIAM MINTS ${ }^{1}$ \\ ${ }^{1}$ Department of Women's and Children's Health, Karolinska University Hospital; \\ ${ }^{2}$ Department of Molecular Medicine and Surgery, Karolinska Institute; ${ }^{3}$ Coagulation Unit, \\ Department of Medicine, Karolinska University Hospital, Stockholm 171 76, Sweden
}

Received August 11, 2015; Accepted December 14, 2015

DOI: $10.3892 / e t m .2016 .3144$

\begin{abstract}
Women with the inherited bleeding disorder von Willebrand's disease (VWD) face gender-specific hemostatic challenges during menstruation. Heavy menstrual bleeding (HMB) can negatively affect their overall life activities and the health-associated quality of life. The purpose of the present study was to investigate whether women with VWD experienced HMB and an impaired health-associated quality of life. The study subjects were recruited from the Coagulation Unit of Karolinska University Hospital. Information was retrieved from various self-administered forms and medical records. Of the 30 women (18-52 years) that were included in the present study, 50\% suffered from HMB, although the majority received treatment for HMB. In addition, almost all the included women perceived limitations in the overall life activities due to menstruation. The health-associated quality of life for women with HMB was significantly lower $(\mathrm{P}<0.10)$ with regards to 'bodily pain' compared with Swedish women of the general population. In conclusion, women with VWD experienced reduced health-associated quality of life as a result of HMB. Therefore, preventing limitations in overall life activities and improving their health-associated quality of life thorough counseling on menstrual bleeding is important for women with VWD.
\end{abstract}

Correspondence to: Professor Miriam Mints, Department of Women's and Children's Health, Karolinska University Hospital, 22 Karolinska Vägen, Stockholm 171 76, Sweden

E-mail: miriam.mints@ki.se

Abbreviations: HMB, heavy menstrual bleeding; LNG-IUS, levonorgestrel-releasing intrauterine system; SF-36, short form-36; PBAC, pictorial blood-loss assessment chart; VWD, von Willebrand's disease; VWF, von Willebrand factor

Key words: von Willebrand's disease, heavy menstrual bleeding, quality of life, bleeding disorders, gynecology, hematology

\section{Introduction}

Von Willebrand's disease (VWD) is the most common inherited bleeding disorder worldwide, with a prevalence varying within $0.1-1 \%$ of the general population depending on the method of diagnosis (1-4). The disorder is caused by a quantitative or qualitative deficiency in the von Willebrand factor (VWF). Since VWD is an autosomal inherited disorder, men and women are equally affected. However, more women experience hemostatic challenges through menstrual bleeding and childbirth (5).

Heavy menstrual bleeding (HMB), which is defined as $>80 \mathrm{ml}$ per menstruation (6), is common in women with VWD. Previous studies have shown that $78-92 \%$ of women with VWD suffer from HMB, compared with a $10 \%$ prevalence of HMB in all Swedish women of reproductive age (7-9).

HMB can be managed through a range of pharmacological treatments, such as contraceptive pills, levonorgestrel-releasing intrauterine systems (LNG-IUS), and tranexamic acid (TA) (10). For women with VWD, treatment with D-arginine vasopressin and VWF/factor VIII concentrates is also an option (11). Despite the availability of extensive pharmacological options, surgical treatment may be necessary (10). Kirtava et al (12) demonstrated that a higher proportion of women with VWD undergo hysterectomy and at a younger age compared with women in the general population.

HMB affects numerous aspects of health-associated quality of life, both physical and mental. It can cause iron-deficiency anemia in severe cases, and there are psychological, social and employment consequences associated with HMB (13). Barr et al (14) demonstrated that women with VWD participate less in post-secondary education than the general population, and suggested that this may be due to iron deficiency resulting from HMB. Côté et al (15) reported that HMB is also associated with a marked work loss and has important economic implications for women.

The majority of studies that have been conducted on women with VWD are case series using few patients from separate or solitary hospitals, and the incidence of HMB in women with VWD in Sweden remains uncertain. Furthermore, little is known about how such women perceive their health-associated quality of life, and whether there may be a potential benefit in 
a closer cooperation between hematologists and gynecologists. The purpose of the present study was to investigate whether women in Stockholm diagnosed with VWD experience HMB and an impaired health-associated quality of life.

\section{Materials and methods}

Patients. The study subjects were recruited from a local register for patients with VWD at the Coagulation Unit of Karolinska University Hospital (Stockholm, Sweden). It was optional for patients to be a part of the register, but all patients were asked to participate. The local register was searched, having set the inclusion criteria to a diagnosis of VWD, female gender and an age of 18-52 years [which is the mean age for menopause in Sweden (16)]. A total of 30 women were included in the present study.

Treatments. Patients received one of the following treatment options: TA, 12 patients; desmopressin, 5 patients; LNG-IUS, 5 patients; progesterone contraceptive pills (PCP), 4 patients; $\mathrm{VWF} /$ factor VIII, 2 patients. It is of note that the efficacy of treatment varies between different types of VWD and between patients, so it is difficult to predict the outcome of treatment (17).

TA prevents the conversion of plasminogen to plasmin by inhibiting the binding of plasminogen to fibrin, generating an antifibrinolytic effect. This is administered intravenously, orally or locally (18). TA alone may be sufficient to control mucosal bleeds, and is often used to amplify the effect of desmopressin D-arginine vasopressin (DDAVP) or VWF/factor VIII concentrates (11).

DDAVP, administered as an intranasal spray or subcutaneous injection, increases the release of endogenous VWF and factor VIII from endothelial cells (19). The response to DDAVP depends on the type of VWD; type 1 typically responds well to this, types $2 \mathrm{~A}, 2 \mathrm{M}$ and $2 \mathrm{~N}$ respond to an intermediate degree, and type 3 is unresponsive (20).

LNG-IUS is a hormonal intrauterine device used as an effective form of birth control in addition to treating excessive bleeding during menstruation (21).

PCP is a hormonal method of contraception that does not include estrogens. This may be used for contraception in addition to representing a treatment option for heavy menstruation (22).

VWF/factor VIII concentrates may be administered when the response to DDAVP is insufficient (20). VWF/factor VIII concentrates are administered intravenously, with a controlled ratio of VWF to factor VIII. These provide prophylaxis for bleeding in patients with severe VWD and prevent bleeding following surgery or trauma (20).

Data collection. A questionnaire, a pictorial blood-loss assessment chart (PBAC) to assess HMB, and a health survey (SF-36) to evaluate health-associated quality of life were sent to each participant. Background information on the type of VWD and any pharmacological treatment that the patients had received was retrieved from their medical records.

The patient administered questionnaire was used to investigate whether the women experienced HMB, the perceived impact of menstruation on overall life activities and the
Table I. Themes in a questionnaire that included 11 different topics regarding various aspects of life associated with HMB.

\begin{tabular}{|c|c|}
\hline Questions & Theme \\
\hline $1-12$ & Life conditions \\
\hline $13-17$ & Menstruation \\
\hline $18-29$ & $\begin{array}{l}\text { Assessment of functioning and health } \\
\text { associated with HMB }\end{array}$ \\
\hline $30-37$ & $\begin{array}{l}\text { Body image and self-esteem associated } \\
\text { with menstruation }\end{array}$ \\
\hline $38-41$ & Sexual relationships \\
\hline $42-60$ & Female sexual function index \\
\hline $61-65$ & Sexuality \\
\hline $66-77$ & Female sexual distress scale \\
\hline $78-87$ & Rosenberg's self-esteem scale \\
\hline $88-101$ & Hospital anxiety and depression scale \\
\hline 102 & Pharmacological treatment for HMB \\
\hline
\end{tabular}

HMB, heavy menstrual bleeding.

pharmacological treatment for HMB. The questionnaire consisted of 102 questions on 11 themes (Table I) and was originally developed by a research group at the Coagulation Unit at Karolinska University Hospital during an unpublished study on health-associated quality of life in women with HMB. The questions regarding life conditions (questions 1-12) are used in clinical practice at the Coagulation Unit, whereas questions 13-17 were constructed by the research group at the Coagulation Unit and assessed the amount of menstrual blood loss, the duration of menstruation and the need for advice on menstruation. Questions 18-29, which examined the perceived impact of menstruation on overall life activities, originate from studies conducted by Ruta et al (23) and Coulter et al (24). In order to limit the scope of this study to relevant data, questions 30-101 in the questionnaire were not analyzed. These questions explored self-esteem, sexual functioning and mental health more thoroughly and will be examined in a subsequent study.

A PBAC was used to clinically assess the amount of menstrual blood loss and the duration of flow according to the method developed by Higham et al (25), conducted prospectively by comparison of the tampons/pads supplied with a scoring table. A score of $>100$ was interpreted as a HMB.

In order to assess health-associated quality of life, a health survey form, known as a Short Form-36 (SF-36), was used. SF-36 is a widely used health survey constructed to measure health-associated quality of life in eight dimensions with 36 questions (26). The dimensions are presented in Table II. The answers obtained from the 36 questions were scored according to SF-36 algorithms and interpreted according to a SF-36 scale, with a minimum score of 0 and a maximum score of 100 (27). Reference material for Swedish women in the general population was obtained from a previous study (26) and originates from 4,582 Swedish women of 15-93 years, (mean age, 42.7 years).

In order to perform a more thorough analysis, median SF-36 health profiles were drawn for the study population. 
Table II. Health-associated quality of life according to the eight dimensions of Short Form-36 and the definitions of the lowest and highest scores in each dimension.

\begin{tabular}{|c|c|c|}
\hline Dimension & Lowest possible score & Highest possible score \\
\hline Physical functioning & $\begin{array}{l}\text { Very limited, including daily activities } \\
\text { of personal hygiene and dressing }\end{array}$ & $\begin{array}{l}\text { Not limited, can perform all } \\
\text { types of physical activities }\end{array}$ \\
\hline Physical health & $\begin{array}{l}\text { Limited performance at work or regular } \\
\text { activities due to poor physical health }\end{array}$ & $\begin{array}{l}\text { Not limited, can perform } \\
\text { and regular activities work }\end{array}$ \\
\hline Bodily pain & Severe pain & No pain \\
\hline General health & $\begin{array}{l}\text { Perceives general health status as poor } \\
\text { and believes it will deteriorate }\end{array}$ & $\begin{array}{l}\text { Perceives general health } \\
\text { status as excellent }\end{array}$ \\
\hline Vitality & Feels constantly tired and worn out & $\begin{array}{l}\text { Feels constantly alert and } \\
\text { energetic }\end{array}$ \\
\hline Social functioning & $\begin{array}{l}\text { Limited in social activities due to } \\
\text { physical or mental health status }\end{array}$ & $\begin{array}{l}\text { Not limited, can maintain } \\
\text { normal social activities }\end{array}$ \\
\hline Emotional impact & $\begin{array}{l}\text { Limited in work and regular } \\
\text { activities due to emotional status }\end{array}$ & $\begin{array}{l}\text { Not limited, can perform } \\
\text { work and regular activities }\end{array}$ \\
\hline Mental health & Feels constantly depressed or nervous & $\begin{array}{l}\text { Feels constantly calm, } \\
\text { harmonious and happy }\end{array}$ \\
\hline
\end{tabular}

Table III. Distribution of VWD type 1,2 and 3.

\begin{tabular}{lc}
\hline Parameter & Study population, $\mathrm{n}(\%)$ \\
\hline Total & $30(100)$ \\
VWD type 1 & $15(50.0)$ \\
VWD type 2 & $11(36.7)$ \\
VWD type 3 & $4(13.3)$ \\
\hline
\end{tabular}

Distribution of VWD type 1,2 and 3 in the study population was analyzed and no significant differences in their distribution were identified $(\mathrm{P}>0.05)$. VWD, von Willebrand's disease.

Median SF-36 scores were calculated in each of the eight dimensions of SF-36 for the total study population and for the following subgroups: Women with VWD type 1, type 2 and type 3 , women with no menstrual bleeding, women with normal menstrual bleeding, and women with HMB.

Statistical analysis. In order to identify the characteristics associated with HMB and the various SF-36 scores, the study population was arranged into subgroups according to the type of VWD and the amount of menstrual bleeding. For the variables for which the answers could be ranked according to an ordinal scale, the average ranking sum was calculated for each subgroup and compared using a non-parametric Kruskal-Wallis test. The null hypothesis was that the populations from which the samples were collected had the same distribution, and therefore had the same median. A statistically significant result $(\mathrm{P}<0.05)$ with the Kruskal-Wallis test indicated that at least one group was different from the others.

The median SF-36 health profiles for the study population and the subgroups were plotted and compared with the median SF-36 health profiles of Swedish women from the general population. In order to detect statistically significant
Table IV. Age distribution in the study population.

\begin{tabular}{lc}
\hline Parameter & Value \\
\hline Total patient number, $\mathrm{n}$ & 30 \\
Mean age $\pm \mathrm{SD}$, years & $35.1 \pm 8.1$ \\
Minimum age, years & 19 \\
Maximum age, years & 51 \\
\hline
\end{tabular}

SD, standard deviation.

differences between the median SF-36 values of the study population and the Swedish women of the general population, approximate confidence intervals with $\mathrm{P}<0.10$ were constructed for the median values of the total study population and the subgroups with $n \geq 15$. The approximate confidence intervals for the median values were obtained through ranking of the SF-36 values in each dimension, and the results obtained were compared to corresponding tabulated ranks (28) for a $90 \%$ confidence interval. A $90 \%$ confidence interval was selected due to the size of the study population and the relatively low number of ranks obtained.

Ethical approval. The questionnaire was accompanied by a letter explaining how and why the study was being performed and that participation was voluntary, and written informed consent was obtained from the patients. Ethical permission for the present study was granted by the Central Ethical Review Board of Karolinska Institute, Stockholm, Sweden (ethical permission registration no. 2007/1373-31/4).

\section{Results}

Characteristics of the study population. The characteristics of the study population (30 women with VWD) were analyzed 
Table V. Amount of menstrual bleeding in women with VWD type 1, 2, and 3.

\begin{tabular}{lccccc}
\hline $\begin{array}{l}\text { Menstrual } \\
\text { bleeding }\end{array}$ & $\begin{array}{c}\text { Total }(\mathrm{n}=30), \\
\mathrm{n}(\%)^{\mathrm{a}}\end{array}$ & $\begin{array}{c}\text { HMB } \\
\text { incidence, } \mathrm{n}^{\mathrm{b}}\end{array}$ & $\begin{array}{c}\text { VWD type 1 } \\
(\mathrm{n}=15), \mathrm{n}(\%)\end{array}$ & $\begin{array}{c}\text { VWD type 2 } \\
(\mathrm{n}=11), \mathrm{n}(\%)\end{array}$ & $\begin{array}{c}\text { VWD type 3 } \\
(\mathrm{n}=4), \mathrm{n}(\%)\end{array}$ \\
\hline None & $8(26.7)$ & 0 & $3(20.0)$ & $3(27.2)$ & $2(50.0)$ \\
Normal & $7(23.3)$ & 5 & $2(13.3)$ & $4(36.4)$ & $1(25.0)$ \\
HMB & $15(50.0)$ & 11 & $10(66.7)$ & $4(36.4)$ & $1(25.0)$ \\
\hline
\end{tabular}

${ }^{a}$ Incidence of no menstrual bleeding, normal menstrual bleeding and HMB, based on the women's reports of their own experience. ${ }^{b}$ Incidence of HMB based on clinical measurements of frequency of menses, duration of flow, and volume of monthly blood loss. VWD, von Willebrand's disease; HMB, heavy menstrual bleeding.

Table VI. Pharmacological treatment of HMB. The number of women who received pharmacological treatment for HMB, the type of treatment they received, and the resulting menstrual bleeding based on clinical measurements.

\begin{tabular}{|c|c|c|c|c|c|c|c|c|}
\hline \multirow{2}{*}{$\begin{array}{l}\text { Clinical } \\
\text { menstrual bleeding }\end{array}$} & \multicolumn{2}{|c|}{ Treatment, $\mathrm{n}$} & \multicolumn{6}{|c|}{ Type of pharmacological treatment, $n$} \\
\hline & Yes & No & LNG-IUS & PCP & DDAVP & $\mathrm{TA}$ & VWF/FVIII & Other \\
\hline None $(n=8)$ & 5 & $3^{\mathrm{a}}$ & 4 & $1^{\mathrm{b}}$ & 0 & 0 & 0 & 0 \\
\hline Normal $(n=6)$ & 5 & 1 & 1 & 1 & 4 & 0 & 0 & 1 \\
\hline $\operatorname{HMB}(n=16)$ & 14 & 2 & 0 & 2 & 1 & 12 & 2 & 0 \\
\hline Total $(n=29)^{c}$ & 24 & 6 & 5 & 4 & 5 & 12 & 2 & 1 \\
\hline
\end{tabular}

${ }^{\mathrm{a}}$ Reason for no menstruation: Pregnancy or breastfeeding (two cases) and surgery (one case). ${ }^{\mathrm{b}}$ Continuous treatment with no monthly break. ${ }^{\mathrm{c}}$ One patient had $>1$ treatment. HMB, heavy menstrual bleeding; LNG-IUS, levonorgestrel-releasing intrauterine system; PCP, progesterone contraceptive pills; DDAVP, desmopressin D-arginine vasopressin; TA, tranexamic acid; VWF/FVIII, von Willebrand factor/factor VIII concentrates.

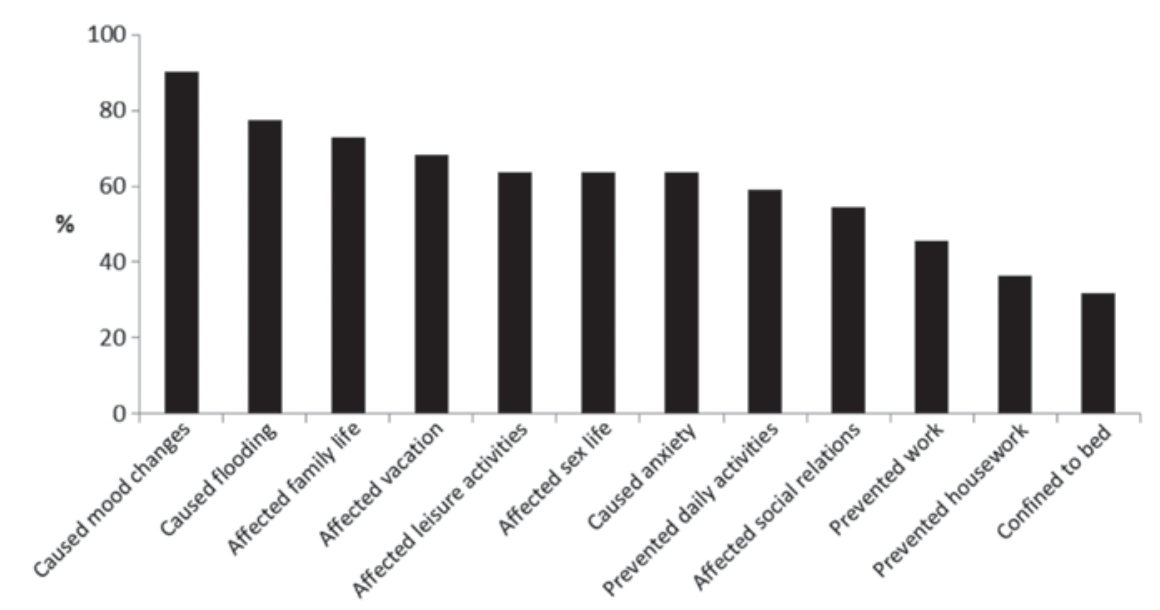

Figure 1. Impact of menstruation on overall life activities in the group of women with von Willebrand's disease and menstruation ( $\mathrm{n}=22)$.

with regard to the type of VWD and age. No statistically significant differences were observed in the distribution of VWD types between the patients (Tables III and IV).

$H M B$ in women with $V W D$. The amount of menstrual bleeding based on the woman's own experience, the incidence of HMB, and clinical measurements, including frequency of menses, duration of flow and volume of monthly blood loss, for the study population is presented in Table V. The incidence of HMB based on the women's personal evaluations was shown to be $50.0 \%$ in the study population $(n=30)$. The incidence of HMB based on clinical measurements was shown to be $53.3 \%$. Of the 15 women who reported HMB, $73.3 \%$ had clinical measurements consistent with HMB. Of the women who reported normal menstrual bleeding, $71.4 \%$ were revealed to have clinical measurements that were consistent with HMB.

In the study population, $66.7 \%$ of the women with VWD type 1 reported HMB compared with $36.4 \%$ of the women with VWD type 2 and $25.0 \%$ of the women with VWD type 3. Likely due to the small size of the subgroups, no significant 

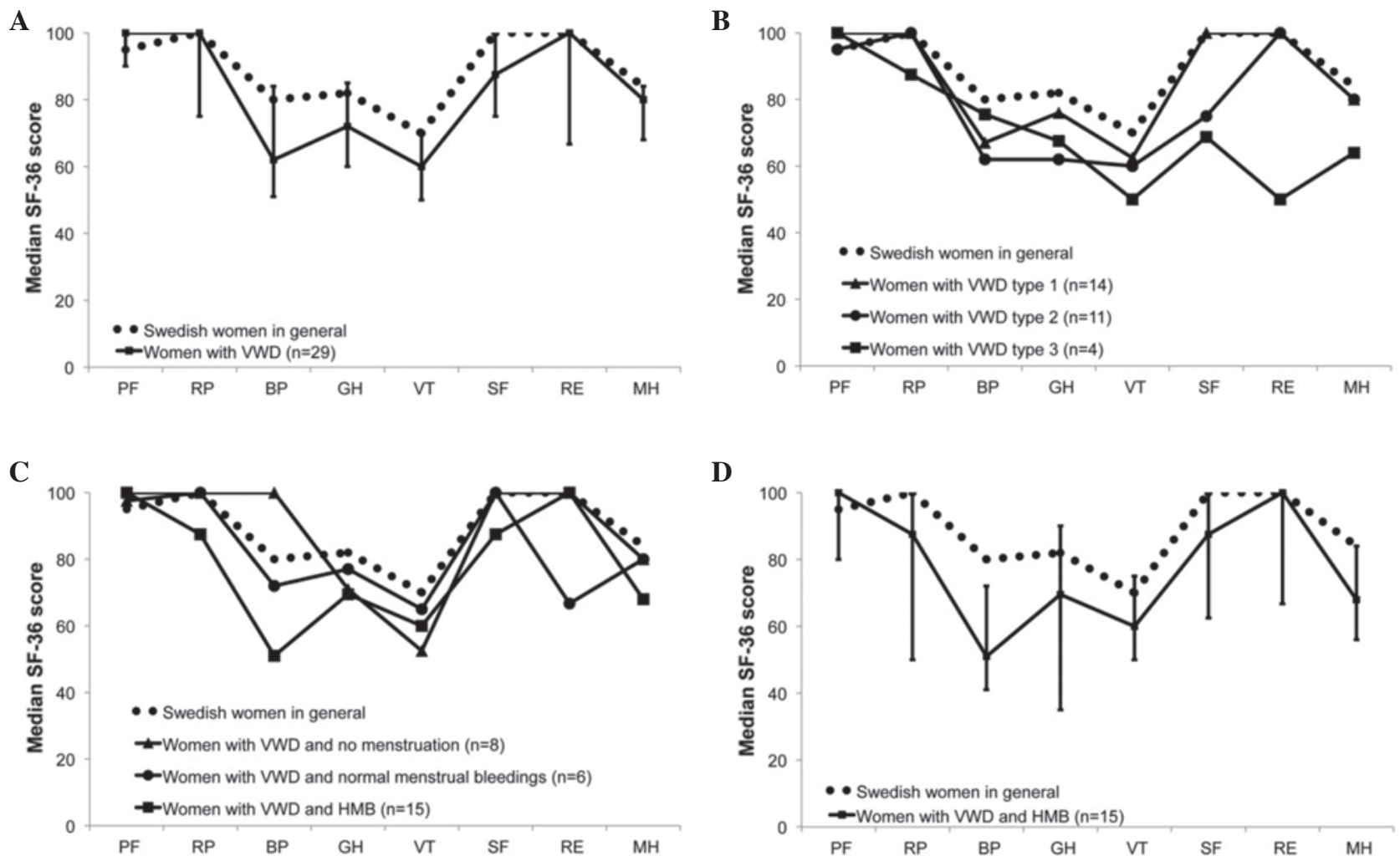

Figure 2. Health profiles for the study population. Median SF-36 scores in each dimension of SF-36 presented as health profiles for the total study population and subgroups of the study population. (A) The health profile of the total study population compared with the health profile of Swedish women of the general population. Error bars represent the approximate confidence interval $(\mathrm{P}<0.10)$ for the median SF-36 scores of the study population. (B) The health profiles for women with VWD type 1,2 and 3 compared with the health profile of Swedish women in the general population. (C) The health profiles of women with no menstrual bleeding, normal menstrual bleeding and HMB compared with the health profile of Swedish women in the general population. (D) The health profiles of women with HMB compared with the health profiles of Swedish women in the general population. Error bars represent the approximate confidence interval $(\mathrm{P}<0.10)$ for the median SF-36 scores of women with HMB. VWD, von Willebrand's disease; HMB, heavy menstrual bleeding; PF, Physical Functioning; RP, role-physical; BP, bodily pain; GH, general health; VT, vitality; SF, social functioning; RE, role-emotional; MH, mental health.

differences $(\mathrm{P}>0.05)$ were observed when comparing the amount of menstrual bleeding in women with VWD type 1, 2 and 3. The reasons for having no menstrual bleeding were pregnancy or breastfeeding ( 2 women), treatment with LNG-IUS (4 women), continuous treatment with contraceptive pills ( 1 woman) and surgery (1 woman). In total, 5 women experienced their menstrual bleeding as normal, although they had clinical measurements consistent with HMB. Furthermore, 4 women reported their menstruation as HMB, although they lacked clinical measurements consistent with HMB (Table V).

Treatment for HMB. The majority of the women $(24 / 30 ; 80.0 \%)$ received pharmacologic treatment for HMB (Table VI). Based on clinical measurements of menstrual bleeding, the treatment was demonstrated to be effective in 10/24 (41.7\%) of the cases, whereas based on the women's evaluation, treatment was considered to be effective in $15 / 24(62.5 \%)$ of the cases (data not shown). Only 3 women with menstruation did not receive any pharmacological treatment for HMB, and 2 of these had clinical measurements consistent with HMB (Table VI).

Impact of menstruation on overall life activities. The perceived impact of menstruation on overall life activities was found to be substantial (Fig. 1). The data showed that of the 22 women with menstruation, 1 woman reported no limitations in overall life activities, 2 women reported limitations in less than three areas of overall life activities, and the remaining 19 women reported limitations in three areas or more of their overall life activities. Menstruation was reported to affect women in a high percentage of cases in the following ways: Mood changes $(90.9 \%)$, heavy bleeding $(77.3 \%)$, family life (72.7\%) and vacations (68.2\%), with over two thirds of women with VWD reporting limitations in these areas. Menstruation also affected leisure activities (63.6\%) and sex life (63.6\%), caused anxiety (63.6\%), prevented daily activities (59.1\%)and markedly affected social relations (54.5\%), with over half of the women reporting these limitations. Approximately half of the women $(45.5 \%)$ reported that their ability to work was negatively affected by menstruation. The ability to carry out housework was less affected by menstruation, although more than one third (36.4\%) reported limitations. Approximately one third of women $(31.8 \%)$ with VWD were confined to bed for over half a day during the menstrual period.

Health-associated quality of life. Completed SF-36 health surveys were received from 29 of the 30 women in the study population. Median SF-36 health profiles for the total study population and for the subgroups for women with VWD type 1,2 and 3, and women with no menstrual bleeding, normal menstrual bleeding and HMB, are presented in Fig. 2. Significant differences were not identified in any of the eight dimensions of SF-36 when the median SF-36 scores of the 
total study population were compared with the median SF-36 scores of Swedish women in the general population (Fig. 2A). However, in the SF-36 dimension of vitality, the score of the Swedish women in the general population was equal to the upper limit of the confidence interval for women with VWD, and the statistical difference was almost reached statistically significant. The median SF-36 scores of women with VWD type 1,2 and 3 appeared to be lower compared with the scores of Swedish women in the general population, although no significant differences were be identified (Fig. 2B). The median SF-36 scores of women with no menstruation, normal menstrual bleeding and HMB were compared separately with the median SF-36 scores of Swedish women in the general population (Fig. 2C). In the dimension of bodily pain, the group of women with HMB had significantly lower scores compared with those of women in the general Swedish population (Fig. 2D). This implies that the women in the study population with HMB experienced an impaired health-associated quality of life due to pain.

Comparison of the SF-36 scores between the types of VWD demonstrated the absence of significant differences in SF-scores between women with VWD type 1,2 and 3. Similarly, according to the amount of menstrual bleeding, there were no significant differences in the SF-36 scores between women without menstruation, with normal menstrual bleeding and with HMB.

\section{Discussion}

The present study presented two important results: Firstly, women with VWD were found to experience severe HMB, although the majority of these women were receiving pharmacologic treatment. Therefore, the pharmacologic treatment of HMB in women with VWD appears to be insufficient, and requires optimization. Secondly, the perceived impact of menstruation on the overall life activities was demonstrated to be substantial, and the majority of women in the study population were limited in several areas. The health-associated quality of life was lower in the study population compared with the Swedish women in the general population. A significant difference was identified in the bodily pain SF-36 dimension in the study population with HMB, as compared with Swedish women in the general population.

The study population was carefully selected from the Coagulation Unit at the Karolinska University Hospital, and all women had a known and documented diagnosis on the type of VWD. Therefore, despite the small size of the study population, the selection process may still be regarded as a strength of the present investigation.

The incidence of HMB in the present study (50.0-53.3\%) was concordant with the results of recent studies performed by Rae et al (29), Byams et al (30) and Kirtava et al (12) that reported incidence of 45.2,51.7 and 44\%, respectively. Regarding the study population, the women in the aforementioned studies were connected to hematology centers, as in the present study.

Among the 22 women with menstruation, 5 women evaluated their menstrual bleeding as normal although their PBAC scores were consistent with HMB. One possible explanation is that their menstruation was decreased (but remained heavy) following treatment with TA for instance, as compared with their menstruation flow prior to treatment, and hence they considered it normal. Another explanation may be that they compared their menstruation to that of their mother or sister, and taking into account the hereditary nature of VWD, this assessment may be false. Among the 22 women with menstruation, 4 women experienced their menstruation as HMB though they lacked clinical measurements consistent with HMB.

Women with VWD who were treated with LNG-IUS had no or normal menstrual bleeding, whereas women treated with TA continued to have HMB. These results were concordant with a long-term follow-up (5 years) study conducted by Chi et al (31) on LNG-IUS in 18 women with HMB, who had inherited bleeding disorders and a median PBAC score of 255 . Follow-up demonstrated that $42 \%$ of the women had no menstrual bleeding, and the remaining had a PBAC score of $<100$, indicating normal menstrual bleeding (31). In a recent review on TA for the treatment of $\mathrm{HMB}$, Leminen et al (32) compared the effect of TA to that of LNG-IUS, and concluded that TA was significantly less effective than LNG-IUS at reducing $\mathrm{HMB}$. In addition, TA reduced menstrual bleeding by $47 \%$ compared with $83 \%$ following treatment with LNG-IUS.

The number of women with VWD and HMB treated with LNG-IUS appears to be low. The reasons for this are various, and may include a cautious view among women on hormonal contraceptives, a wish to get pregnant or not having received appropriate counseling on menstrual bleeding, thus indicating an importance of thorough counseling from gynecologists.

Women with VWD perceived limitations in overall life activities due to menstruation. These results were concordant with those of previous studies, which demonstrated that a higher number of women with VWD compared with women in the general population perceived limitations in their overall life activities due to menstruation $(12,29)$. Kirtava et al (12) performed a case control study on 62 women with VWD and demonstrated that $23(32.1 \%)$ of these women perceived menstrual bleeding to limit their overall life activities and negatively affect their lives. Among the 70 controls of the study, only 7 women (10.0\%) perceived limitations (12). A study performed by Rae et al (29) concluded that among 84 women with inherited bleeding disorders and HMB, the majority (77.5\%) reported that menstrual bleeding interfered with daily activities.

The health-associated quality of life according to SF-36 appeared to be lower in the study population compared with Swedish women in the general population. However, the differences in median SF-36 scores were not statistically significant. It is possible that the lack of statistical significance was due to the small sample size of the study population, since several earlier studies demonstrated that women with VWD had lower health-associated quality of life compared with women in the general population $(14,28)$. The studies by Solovieva (33) and de Wee et al (34) reported that the 'vitality' SF-36 dimension was negatively affected in women with VWD. In the present study, women with HMB had a significantly lower SF-36 score in the dimension 'bodily pain'. These results were concordant with those obtained by Rae et al (29) who used the self-administered health survey, Health Utilities Index of Canada. In a group of 84 women with inherited bleeding disorders and HMB, Rae et al (29) demonstrated that the health-associated quality of life scores were lower in the dimensions 'pain' and 'cognition'. They also reported that women with VWD $(n=259)$ experienced 
significantly more pain than women with other bleeding disorders $(n=56)$ and men with VWD $(n=97)$.

To quantify menstrual blood loss, self-reported measurements including information from the questionnaire and PBAC were used. There are conflicting results regarding the accuracy of the PBAC $(35,36)$. However, the PBAC is an easily administrated method that is employed in clinical practice and research on menstrual bleeding.

In conclusion, in the present study, $50.0 \%$ of the study population reported $\mathrm{HMB}$, even though the majority $(80 \%)$ received pharmacologic treatment for $\mathrm{HMB}$. This indicates that treatment does not prevent HMB in numerous cases. In addition, LNG-IUS should be used more as a cessation of menstruation, since it often improves the quality of life. Furthermore, the perceived impact of menstruation on overall life activities was substantial. To prevent unnecessary limitations in overall life activities and health-associated quality of life, thorough counseling regarding menstrual bleeding and pain is important in the care of women with VWD.

\section{Acknowledgements}

The authors of the present study are grateful to Mrs. Elisabeth Berg, Department of Learning, Informatics, Management and Ethics, Karolinska Institute for advice on statistics.

\section{References}

1. Bowman M, Hopman W, Rapson D, Lillicrap D and James P: The prevalence of symptomatic von Willebrand disease in primary care practice. J Thromb Haemost 8: 213-216, 2010.

2. Castaman G, Eikenboom JC, Bertina RM and Rodeghiero F: Inconsistency of association between type 1 von Willebrand disease phenotype and genotype in families identified in an epidemiological investigation. Thromb Haemost 82: 1065-1070, 1999.

3. Rodeghiero F, Castaman G and Dini E: Epidemiological investigation of the prevalence of von Willebrand's disease. Blood 69: 454-459, 1987

4. Werner EJ, Broxson EH, Tucker EL, Giroux DS, Shults J and Abshire TC: Prevalence of von Willebrand disease in children: A multiethnic study. J Pediatr 123: 893-898, 1993.

5. James AH: Von Willebrand disease in women: Awareness and diagnosis. Thromb Res 124 (Suppl 1): S7-S10, 2009.

6. National Institute for Health and Clinical Excellence: Guidance: Heavy Menstrual Bleeding. National Collaborating Centre for Women's and Children's Health (UK). London, 2007.

7. Hallberg L, Högdahl AM, Nilsson L and Rybo G: Menstrual blood loss-a population study. Variation at different ages and attempts to define normality. Acta Obstet Gynecol Scand 45: 320-351, 1966.

8. Lukes AS, Kadir RA, Peyvandi F and Kouides PA: Disorders of hemostasis and excessive menstrual bleeding: Prevalence and clinical impact. Fertil Steril 84: 1338-1344, 2005.

9. Committee on Adolescent Health Care; Committee on Gynecologic Practice: Committee Opinion No. 580: Von Willebrand disease in women. Obstet Gynecol 122: 1368-1373, 2013

10. Davidson BR, Dipiero CM, Govoni KD, Littleton SS and Neal JL: Abnormal uterine bleeding during the reproductive years. J Midwifery Womens Health 57: 248-254, 2012.

11. Lassila R, Holme PA, Landorph A, Petrini P, Onundarson PT and Hillarp A: Nordic haemophilia council's practical guidelines on diagnosis and management of von Willebrand disease. Semin Thromb Hemost 37: 495-502, 2011.

12. Kirtava A, Drews C, Lally C, Dilley A and Evatt B: Medical, reproductive and psychosocial experiences of women diagnosed with von Willebrand's disease receiving care in haemophilia treatment centres: A case-control study. Haemophilia 9: 292-297, 2003.
13. Kuzmina N, Palmblad J and Mints M: Predictive factors for the occurrence of idiopathic menorrhagia: Evidence for a hereditary trait. Mol Med Rep 4: 935-939, 2011.

14. Barr RD, Sek J, Horsman J, Furlong W, Saleh M, Pai M and Walker I: Health status and health-related quality of life associated with von Willebrand disease. Am J Hematol 73: 108-114, 2003.

15. Côté I, Jacobs P and Cumming D: Work loss associated with increased menstrual loss in the United States. Obstet Gynecol 100: 683-687, 2002.

16. Hagstad A. Gynecology and sexuality in middle-aged women. Women Health 13: 57-80, 1988.

17. Sadler JE, Budde U, Eikenboom JC, Favaloro EJ, Hill FG, Holmberg L, Ingerslev J, Lee CA, Lillicrap D, Mannucci PM et al: Update on the pathophysiology and classification of von Willebrand disease: A report of the Subcommittee on von Willebrand Factor. J Thromb Haemost 4: 2103-2114, 2006.

18. Dunn CJ and Goa KL: Tranexamic acid: A review of its use in surgery and other indications. Drugs 57: 1005-1032, 1999.

19. Kaufmann JE and Vischer UM: Cellular mechanisms of the hemostatic effects of desmopressin (DDAVP). J Thromb Haemost 1: 682-689, 2003.

20. Mannucci PM: How I treat patients with von Willebrand disease. Blood 97: 1915-1919, 2001.

21. Bahamondes L, Bahamondes MV and Monteiro I: Levonorgestrel-releasing intrauterine system: Uses and controversies. Expert Rev Med Devices 5: 437-445, 2008.

22. Lethaby A, Irvine GA and Cameron I: Cyclical progestogens for heavy menstrual bleeding. Cochrane Database Syst Rev, 2008.

23. Ruta DA, Garratt AM, Chadha YC, Flett GM, Hall MH and Russell IT: Assessment of patients with menorrhagia: How valid is a structured clinical history as a measure of health status? Qual Life Res 4: 33-40, 1995.

24. Coulter A, Peto V and Jenkinson C: Quality of life and patient satisfaction following treatment for menorrhagia. Fam Pract 11: 394-401, 1994.

25. Higham JM, O'Brien PM and Shaw RW: Assessment of menstrual blood loss using a pictorial chart. Br J Obstet Gynaecol 97: 734-739, 1990.

26. Sullivan M, Karlsson J, Taft C and Ware JE: SF-36 health survey: Swedish manual and interpretation guide. Sahlgrenska University Hospital, Gothenburg, 2002 (In Swedish).

27. Sullivan M, Karlsson J and Ware JE Jr: The Swedish SF-36 health survey - I. Evaluation of data quality, scaling assumptions, reliability and construct validity across general populations in Sweden. Soc Sci Med 41: 1349-1358, 1995.

28. Altman DG: Practical statistics for medical research. Chapman \& Hall, London, 1999.

29. Rae C, Furlong W, Horsman J, Pullenayegum E, Demers C, St-Louis J, Lillicrap D and Barr R: Bleeding disorders, menorrhagia and iron deficiency: Impacts on health-related quality of life. Haemophilia 19: 385-391, 2013.

30. Byams VR, Kouides PA, Kulkarni R, Baker JR, Brown DL, Gill JC, Grant AM, James AH, Konkle BA, Maahs J, et al: Surveillance of female patients with inherited bleeding disorders in United States haemophilia treatment centres. Haemophilia 17 (Suppl 1): 6-13, 2011.

31. Chi C, Huq FY and Kadir RA: Levonorgestrel-releasing intrauterine system for the management of heavy menstrual bleeding in women with inherited bleeding disorders: Long-term follow-up. Contraception 83: 242-247, 2011.

32. Leminen $H$ and Hurskainen R. Tranexamic acid for the treatment of heavy menstrual bleeding: Efficacy and safety. Int J Womens Health 4: 413-421, 2012.

33. Solovieva S: Clinical severity of disease, functional disability and health-related quality of life. Three-year follow-up study of 150 Finnish patients with coagulation disorders. Haemophilia 7: 53-63, 2001.

34. de Wee EM, Mauser-Bunschoten EP, Van Der Bom JG, Degenaar-Dujardin ME, Eikenboom HC, Fijnvandraat K, de Goede-Bolder A, Laros-van Gorkom BA, Meijer K, Raat H, et al: Health-related quality of life among adult patients with moderate and severe von Willebrand disease. J Thromb Haemost 8: 1492-1499, 2010.

35. Zakherah MS, Sayed GH, El-Nashar SA and Shaaban MM: Pictorial blood loss assessment chart in the evaluation of heavy menstrual bleeding: Diagnostic accuracy compared to alkaline hematin. Gynecol Obstet Invest 71: 281-284, 2011.

36. Reid PC, Coker A and Coltart R: Assessment of menstrual blood loss using a pictorial chart: A validation study. BJOG 107: 320-322, 2000. 